\title{
TIG AND LASER BEAM WELDED JOINTS - SIMPLIFIED NUMERICAL ANALYSES
}

\author{
BARBARA NASIEOWSKA \\ Military University of Technology, Institute of Optoelectronics, Warsaw, Poland \\ e-mail: barbara.nasilowska@wat.edu.pl \\ Agnieszka Derewońko, ZdzisŁaw Bogdanowicz \\ Military University of Technology, Faculty of Mechanical Engineering, Warsaw, Poland \\ e-mail: agnieszka.derewonko@wat.edu.pl; zbogdanowicz@wat.edu.pl
}

\begin{abstract}
Regardless of the welding method, a new joint and the surrounding area are inevitably subjected to thermo-physical perturbation. The paper presents analyses of many different issues involved in welding and potential solutions including adoption of simplifying assumptions, application of numerical algorithms and development of reliable representative models. The Finite Element Method is used to determine residual stress distribution, using results from thermo-physical tests and widely known mechanical properties of metals subjected to welding processes. Experimental and numerical methods for determining residual stress are compared for welds generated using both TIG (Tungsten Inert Gas, Gas Tungsten Arc Welding) and a laser beam. This data reveals that it is necessary to precisely define location of the analyzed welded fragment to correctly determine thermal boundary conditions.
\end{abstract}

Keywords: TIG, laser beam, welded joints, steel 904L, numerical analysis, residual stress

\section{Introduction}

During a welding process, the areas around the joints are subjected to thermal and structural changes. Uneven distribution of both temperature and heat flow contributes to a diversity of thermal and mechanical properties of metals. Steel, while being heated only in a narrow areas of joints, increases in volume, thereby resisting to adjacent areas of cold steel and causing thermal stress (Jiao et al., 2014). Thermal stress affects the structural balance, which adds mechanical stress to the already deformed element.

Residual stress in welded joints is an indicator of fatigue life. Two methods are traditionally used to determine these types of stress (Susmel and Tovo, 2008; Zamiri Akhlaghi, 2009). The first method uses mathematical analysis of the nominal stress in constant-amplitude load cases. With the second method, called "hot spot" (Susmel and Tovo, 2008; Zamiri Akhlaghi, 2009), the nominal stress is determined empirically or experimentally using the finite element method (FEM).

Structural changes induced during welding include formation of a geometry notch at the point of stress concentration (Blacha and Karolczuk, 2016). The stress is most concentrated in the "hot spot" at the bottom of the geometry notch of the welded area, potentially resulting in fracture initiation (Kluger and Eagoda, 2016). Stress in pipes of austenitic stainless steel 304 and duplex steel S32750 subjected to a circumferential weld were analyzed in the previous study. Surface tensile stresses in the axis of a circumferential weld prepared using the TIG (Tungsten Inert Gas, Gas Tungsten Arc Welding) method were 250-350 MPa and 350-450 MPa for welds prepared from 304 austenitic stainless steel and S32750 duplex steel, respectively (Lee and Chang, 2014). 
Numerical and experimental evaluation of the heat affected zone as well as the stress of thermal loads and phase transformations in the front welded joint executed with a laser beam, is presented in papers edited by Piekarska and Kubiak (2011, 2013). Temperature-dependent thermo-physical parameters were adopted for a low-carbon weldable steel. Analysis of a three-dimensional numerical model of the temperature field in a welded joint included the movement of the liquid metal in the weld pool and the latent heat associated with the changes of the material state (Tan and Shin, 2015).

Distribution of the residual stress in the cross section at the place of the laser beam impact on the top (face) and bottom (ridge) surface of welds for different welding parameters $v=100 \mathrm{~m} / \mathrm{h}$, $P=3.5 \mathrm{~kW}$ (a) and $v=30 \mathrm{~m} / \mathrm{h}, P=2.0 \mathrm{~kW}$ (b) have also been established in the literature (Tan and Shin, 2015).

Numerical simulation of the residual stress in flat elements made of low-alloy steel buttwelded with a laser beam is shown in (Tan and Shin, 2015; Voss, 2011) in order to illustrate the stress generated in the elements during welding and cooling down to $293 \mathrm{~K}$. Studies have shown that the highest tensile stresses appear in the central part of the welded joint element after cooling (Murakawa, 2013; Ma et al., 2014; Benasciutti et al., 2014; Dong et al., 2014).

The effect of the initial stress generated in the manufacturing process of SUS316 austenitic stainless steel pipeline (diameter $200 \mathrm{~mm}$, length $800 \mathrm{~mm}$, wall thickness $10 \mathrm{~mm}$ ) on the joint welded with a laser beam $(P=12 \mathrm{~kW}, v=1 \mathrm{~m} / \mathrm{min})$ in experimental and mathematical aspects was compared by Voss (2011).

The results revealed that initial stress in the steel prior to the welding process increased the residual stress after welding by approximately 10\%. Despite the widespread use of 904L austenitic stainless steel, there is no thorough comparison between the efficacies of numerical analysis and experimental research in determining the residual stress when welded by using both the TIG and laser beam methodologies.

\section{Experiment}

The research has been carried out on samples of 904L stainless steel welded by the TIG method using infusible MTC MT-904L tungsten electrode $(\emptyset 2.5 \mathrm{~mm})$ and G/W $20255 \mathrm{CuL}(20 \% \mathrm{Cr}$, $25 \% \mathrm{Ni}, 4.5 \% \mathrm{Mo}, 1.5 \% \mathrm{Cu}$ ) weld, according to production technology used i.al. for manufacturing chemical apparatus at the Department of Mechanical Chemical Equipment, Azoty Group in Tarnów.

Table 1. Parameters of 904L welding austenitic stainless steel with a laser beam

\begin{tabular}{|l|c|c|}
\hline \multicolumn{1}{|c|}{ Welding parameters } & IU & Data \\
\hline \hline Focal length of lens & $\mathrm{mm}$ & 260 \\
\hline Spot on sample surface & $\mathrm{mm}$ & $\emptyset 0.4$ \\
\hline Power & $\mathrm{kW}$ & $P=4.5$ \\
\hline Welding speed & $\mathrm{m} / \mathrm{min}$ & $v=1.4$ \\
\hline Protective gas & - & helium \\
\hline
\end{tabular}

The weld has been made with three weldments (Fig. 1c). After chamfering the edges $V$ (Fig. 1a), welding with two weldments from the face side was performed (Fig. 1c -1 and 2), then the ridge was cut (Fig. 1b - grinding) and welded (Fig. 1c - 3).

Joints made with a laser beam $(45 \times 15 \times 5 \mathrm{~mm})$ were prepared using $\mathrm{CO}_{2}$ laser TRIUMF 1005, with parameters shown in Table 1, at the Centre for Laser Technologies of Metals.

The experimental tests of the residual stress of welded joints were conducted at the Institute of Non-Ferrous Metals, Light Metals Division in Skawina (Fig. 2). 

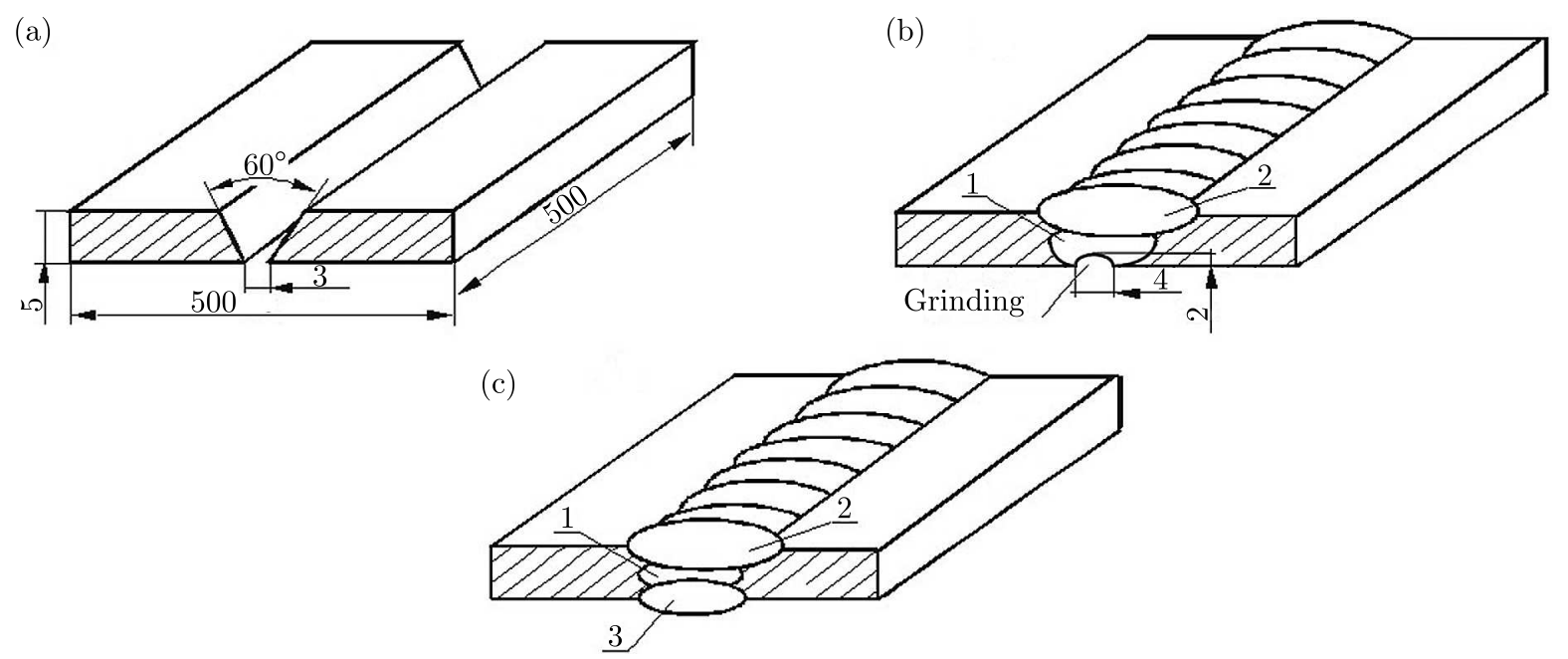

Fig. 1. Geometry of components preparation of a metal sheet before TIG welding of steel 904L (a) and scheme of ridge cutting (b) and welding (c) according to technology used at the Chemical Equipment Plant Construction - Group Azoty in Tarnów

Measurements of the residual stresses (second type $\sigma^{S}$ - balancing within the crystallites area) have been performed on the surface of the samples in the weld (W), the heat affected zone (HAZ) and the base material (BM) for welds made using the TIG and laser beam methods. $\sigma_{x}$ transverse and longitudinal $\sigma_{y}$ distributions of the residual stress were assessed, and numerical analyses were performed using FEA (finite element analysis).

\section{Subject of research}

The subject of research was austenitic stainless steel $904 \mathrm{~L}$ (containing \%: Ni 24-26, Cr 19-21,

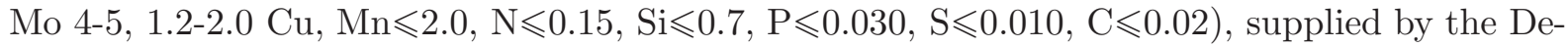
partment of Mechanical Chemical Equipment Group Azoty in Tarnów, produced by Outokumpu Stainless AB in Stockholm, Sweden (Fig. 2) (PN-EN 10088).

\section{Experimental study of residual stress}

Test results of the residual stress for a joint made with a laser beam are shown in Fig. 3a. The stress component perpendicular to the axis of the joint $\sigma_{x}$ for the joint $(\mathrm{S})$ and the heat affected zone (HAZ) are compressive stresses. However, a component parallel to the axis of the joint $\sigma_{y}$ is tensile stress with the highest value detected in the HAZ equal to $\sigma_{y}=296 \mathrm{MPa}$.

For welds made by the TIG method, the component $\sigma_{x}$ is tensile. The maximum value of it is $282 \mathrm{MPa}$, and in the heat affected zone $\sigma_{x}=123 \mathrm{MPa}$.

In the zone of the base material (BM) there occurred compressive stresses for samples welded with the laser beam method $\sigma_{x}=-279 \mathrm{MPa}, \sigma_{y}=-250 \mathrm{MPa}$, and with the TIG method $\sigma_{x}=-143 \mathrm{MPa}, \sigma_{y}=-279 \mathrm{MPa}$ (Fig. 3).

\section{Numerical FEM analysis of welded joints}

Attempts to carry out numerical analyses of the weld cooling phase after the process of TIG and laser beam welding are presented in (Fig. 4). The cooling was achieved by introducing a nonlinear function of temperature in time in the form of piecewise linear representation. Thermo- 


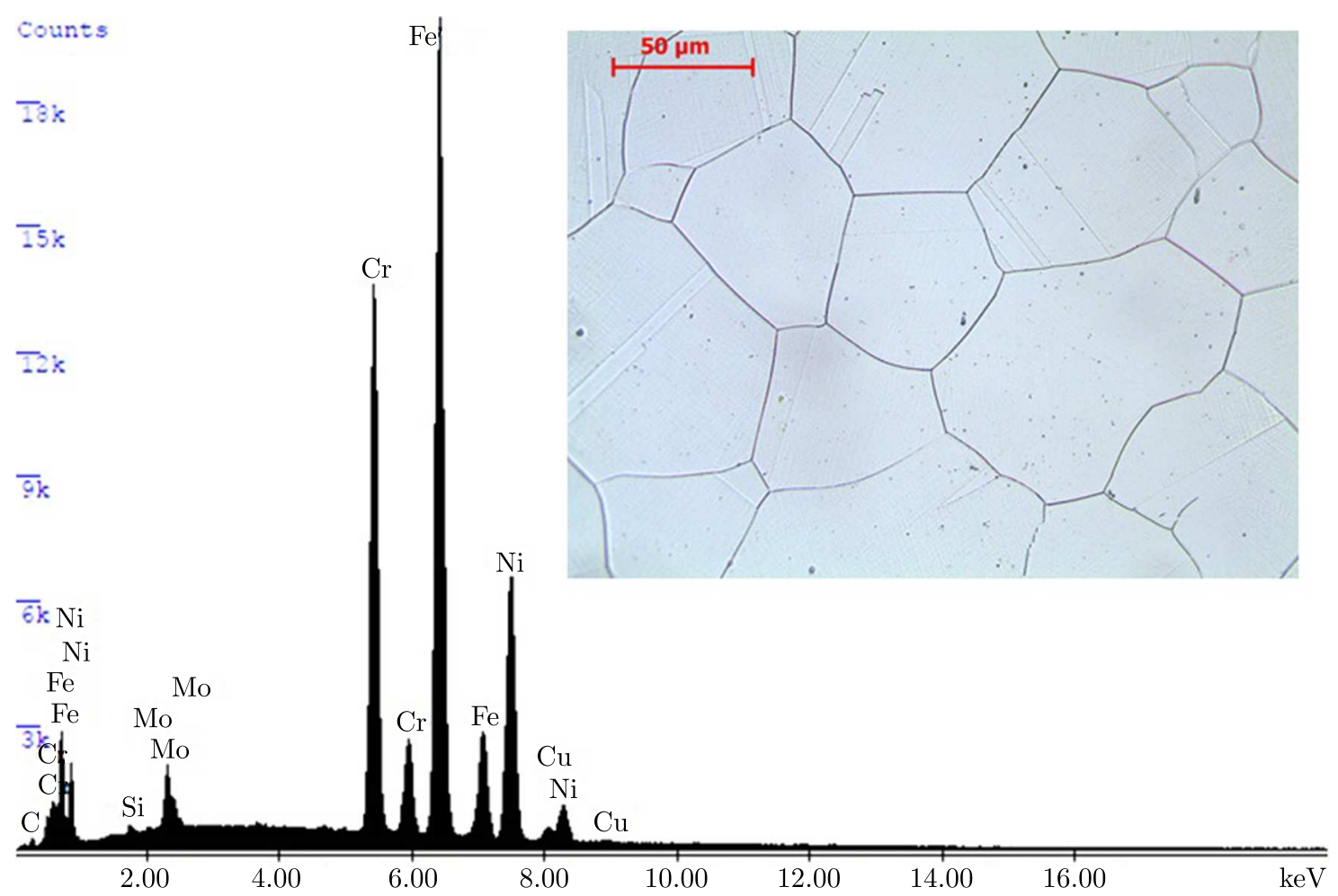

Fig. 2. An example of chemical composition of steel $904 \mathrm{~L}$

(a)

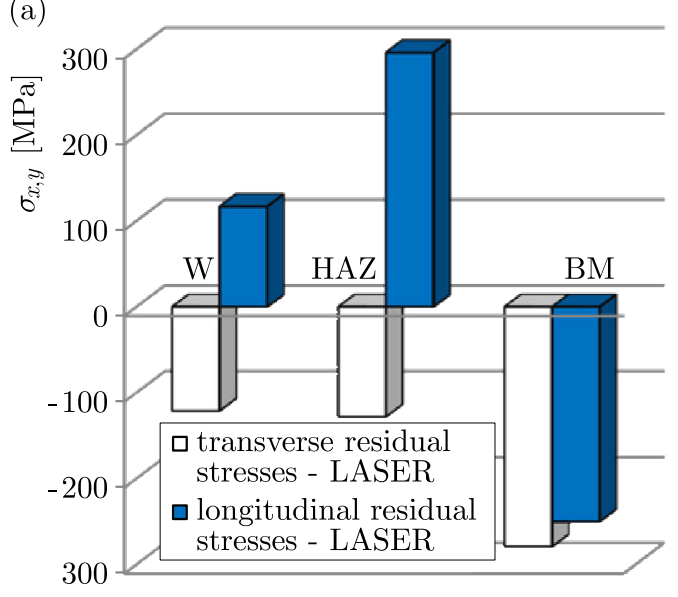

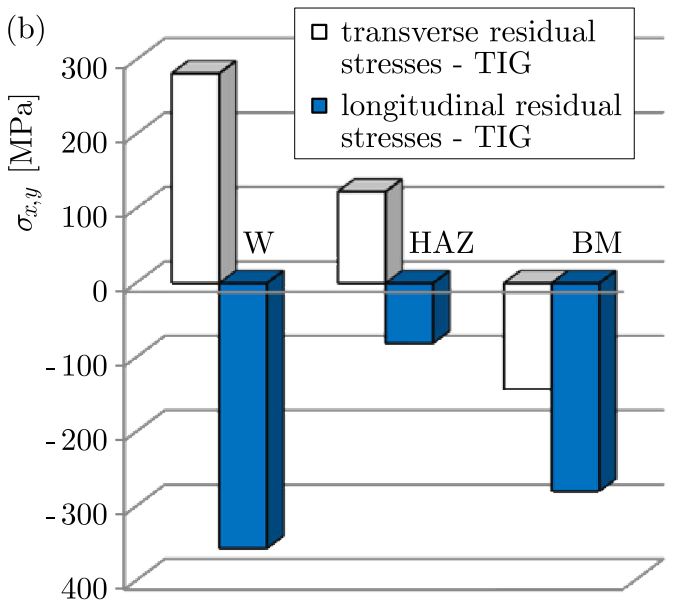

Fig. 3. Residual stress in the weld (W), in the heat affected zone (HAZ) and in the base material (BM) of joints made with the laser beam and TIG methods in the $x$-axis (a) and $y$-axis (b)

-mechanical coupling occurring between thermal and mechanical boundary conditions was applied in the analyses.

The fully coupled problems, where the thermal solution affects the structural solution and the structural solution affects the thermal solution, are presented by a general scheme shown in Fig. 4.

The coupling between thermal and mechanical phenomena depends on material properties and temperature distribution resulting from the welding process, which is the source of data for analysis of transient heat transfer. Mechanical equilibrium equations are introduced assuming a quasi-stationary load process. 


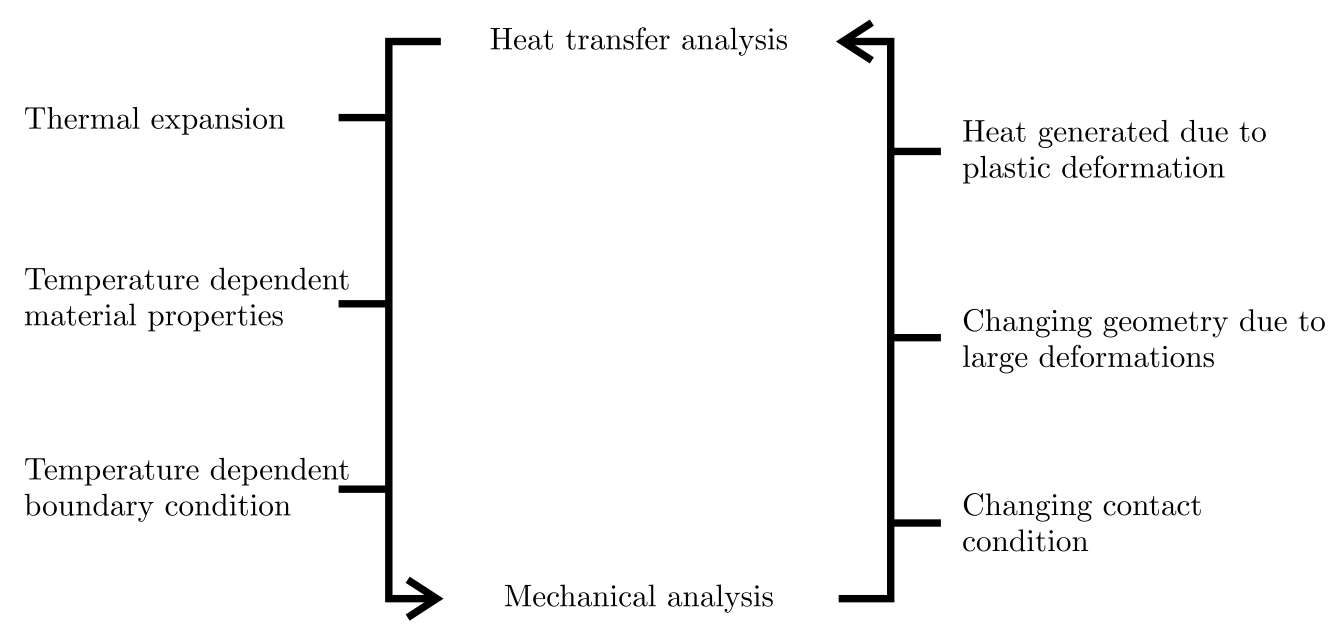

Fig. 4. Schematic of coupled thermo-mechanical analyses

Mathematical formulation of heat transfer with the diffusion and convection part in the tensor form is based on the energy conservation law

$$
\rho c_{p} \frac{\partial T}{\partial t}+\rho c_{p}^{\mathrm{T}} \nabla T-\nabla^{\mathrm{T}}(\boldsymbol{\Lambda} \nabla T)=Q
$$

where $\rho$ is mass density, $c_{p}$ - specific heat, $\boldsymbol{\Lambda}$ - conductivity tensor, $T$ - temperature, $t$ - time and $Q$ is a heat source or heat sink. $v$ is the velocity field calculated by coupling a momentum balance application mode such as incompressible Navier-Stokes. The gradient operator $\nabla$ is given by $\nabla=\left(\frac{\partial}{\partial x}, \frac{\partial}{\partial y}, \frac{\partial}{\partial z}\right)$.

The initial condition and prescribed temperature in transient analysis are defined by

$$
T=T_{i}(x, t) \quad T(x, 0)=T_{i}(x)
$$

where $x$ denotes space coordinates.

Thermal boundary conditions for weld cooling are described by convective heat transfer to the environment. They are given by

$$
-\lambda \frac{\partial T}{\partial n}=h\left(T-T_{\infty}\right)
$$

where $h$ is the film coefficient, $T_{\infty}$ - environmental temperature.

The temperature $\mathbf{T}(x, t)$ in the given element is interpolated from nodal values $\mathbf{T}(t)$ of the element by shape functions $\mathbf{N}(x)\left(\operatorname{Marc}{ }^{\circledR}, 2011\right)$

$$
\mathbf{T}(x)=[\mathbf{N}(x)]^{\mathrm{T}} \mathbf{T}
$$

The equation used for heat transfer is given by (Marc $\AA$, 2011)

$$
\mathbf{C}(\mathbf{T}) \dot{\mathbf{T}}+\mathbf{K}(\mathbf{T}) \mathbf{T}=\mathbf{Q}
$$

where $\mathbf{T}$ is the vector of nodal temperatures (time derivative of the temperature vector), $\mathbf{Q}$ - heat flux vector for the node, $\mathbf{C}(\mathbf{T})$ - matrix of heat capacity, $\mathbf{K}(\mathbf{T})$ - conductivity and convection matrix, $\mathbf{C}(\mathbf{T})$ and $\mathbf{K}(\mathbf{T})$ are dependent on temperature.

The Galerkin method is used to write a coupled set of first order ordinary differential equation (5.6) of the heat transfer problem. 
The transient solution is obtained by using a backward difference scheme

$$
\left[\frac{1}{\Delta t} \mathbf{C}\left(\mathbf{T}^{*}\right)+\mathbf{K}\left(\mathbf{T}^{*}\right)\right] \mathbf{T}^{n}=\mathbf{Q}\left(\mathbf{T}^{*}\right)+\frac{1}{\Delta t} \mathbf{C}\left(\mathbf{T}^{*}\right) \mathbf{T}^{n}
$$

where $\mathbf{T}^{*}$ is an average nodal temperature vector.

In the time increment $\Delta t$, the first iteration within the increment $n$ and is taken as an extrapolated value of the previous two increments: $n-1$ and $n-2$

$$
\mathbf{T}^{*}=\frac{1}{2}\left(3 \mathbf{T}^{n-1}+\mathbf{T}^{n-2}\right)
$$

$\mathbf{T}^{*}$ follows from

$$
\mathbf{T}^{*}=\frac{1}{2}\left(\mathbf{T}^{n-1}+\mathbf{T}^{n}\right)
$$

for next iterations. The iterations are stopped when

$$
\left\|\mathbf{T}_{i-1}^{*}-\mathbf{T}_{i}^{*}\right\|_{\max } \leqslant \Delta \mathbf{T}_{t o l 3}
$$

where $\Delta \mathbf{T}_{\text {tol3 }}$ is the maximum error in the estimated nodal temperature.

The changing geometry due to thermal deformation caused an effect called the large strain. The element and load matrices are derived using an Updated Lagrangian formulation.

The geometric shape was mapped based on the images of metallographic transverse specimens of a weld made with the laser beam (Fig. 5a) and TIG (Fig. 5b) methods.

(a)

Weld made with a laser beam
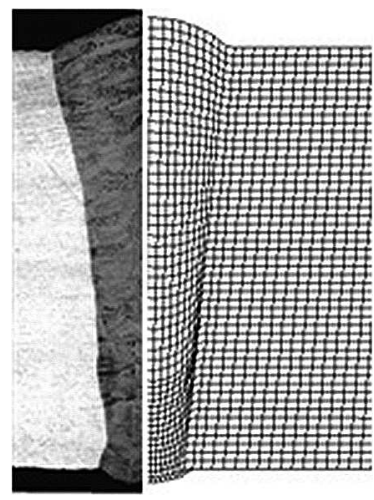

FEM mesh model

a weld made with

a laser beam method

(b)

Weld made with TIG method

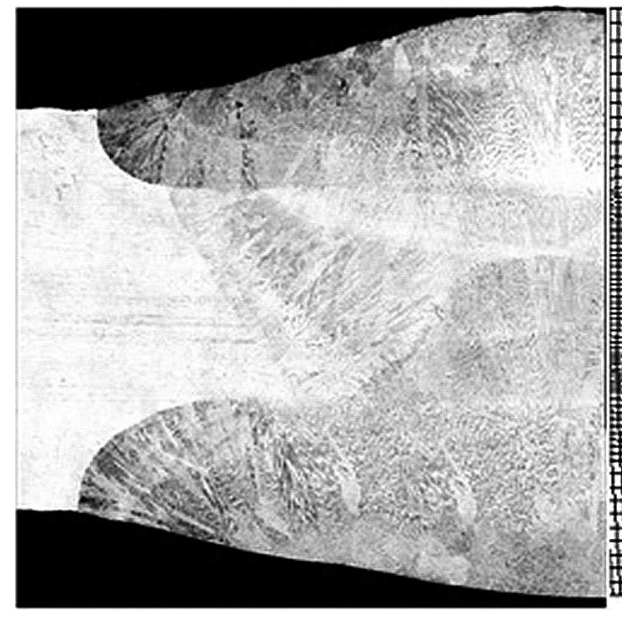

FEM mesh model of a weld made with TIG method

Fig. 5. Finite element mesh of welds made with the laser beam (a) and TIG (b) methods 
It is assumed that the shape of the model made with both TIG and the laser beam method is not symmetrical.

The geometry of the finite models reflecting a part of the actual shape of the welds made with the laser and TIG methods has been divided into 280560 and 408625 isoparametric hexahedral (solid) finite elements described with trilinear shape functions, respectively. The stiffness of the solid element is formed using eight-point Gaussian integration. The use of such elements allows for coupled thermomechanical analysis.

The average edge length of a single finite element in this area is $0.02 \mathrm{~mm}$. Due to necessity to create elements with small dimensions of the weld area, it is possible to map only a part of the welded metal sheets with a width of $5 \mathrm{~mm}$.

To create the model, the following simplifications have been introduced:

a) neglecting non-essential external influences (e.g. welding grips),

b) simplification of shapes of the areas under consideration,

c) neglecting the welding shrinkage,

d) assumption that materials density is constant in time and homogeneous in the whole area,

e) neglecting phase transitions and liquid-solid transformation,

f) assumption of homogeneity of the part contained in a given area for:

- Young's modulus E(T) (PN-EN 19988)

- Poisson's ratio $\nu(T)$ (Jiao et al., 2014)

- thermal conductivity $\lambda(T)$ (Nasiłowska, 2016)

- thermal diffusivity $T$ (Nasiłowska, 2016)

- specific heat $T$ (Nasiłowska, 2016).

Four zones are extracted:

a) base material (BM),

b) heat affected zone (HAZ),

c) joint core (S1, W1-weld),

d) residual weld zone (S2, W2-weld).

The physical properties of the austenitic stainless steel are defined based on standards (PNEN 19988), analysis of the literature (Piekarska, 2007; Ranatowski, 2009) and our in-house studies (Bogdanowicz et al., 2015). These properties, both mechanical and thermal are introduced as a function of temperature. The same parameters have been adopted for each designated zone of the weld.

The temperature load as a function of time has been introduced in each zone of the weld. Nonlinear curves for the weld prepared with the laser beam (Piekarska, 2007) and TIG (Ranatowski, 2009) methods are shown in Figs. 6a and 6b.

In the case of welding with the laser beam, in the core of the weld (W1) and in the residual weld zone (W2), the maximum temperature exceeds the melting point of the steel. Therefore, each of these two curves is divided into two parts: above and below the melting point assumed as $1420 \mathrm{~K}$. In the other two zones, the maximum temperatures do not exceed the melting point of the steel; therefore, they are left in the form shown in Fig. 6.

It is assumed that the environment (air) affects the surface of the weld model on its face and the ridge side, and cools the joint. The ambient temperature of $293 \mathrm{~K}$ has been assumed in the two control points by using the POINT FLUX option. It is assumed that cooling influences only the nodes of the upper and lower walls of the sample discrete model.

In order to map the real welding conditions, there are boundary conditions (support) given based on the structure of the welding torches. 

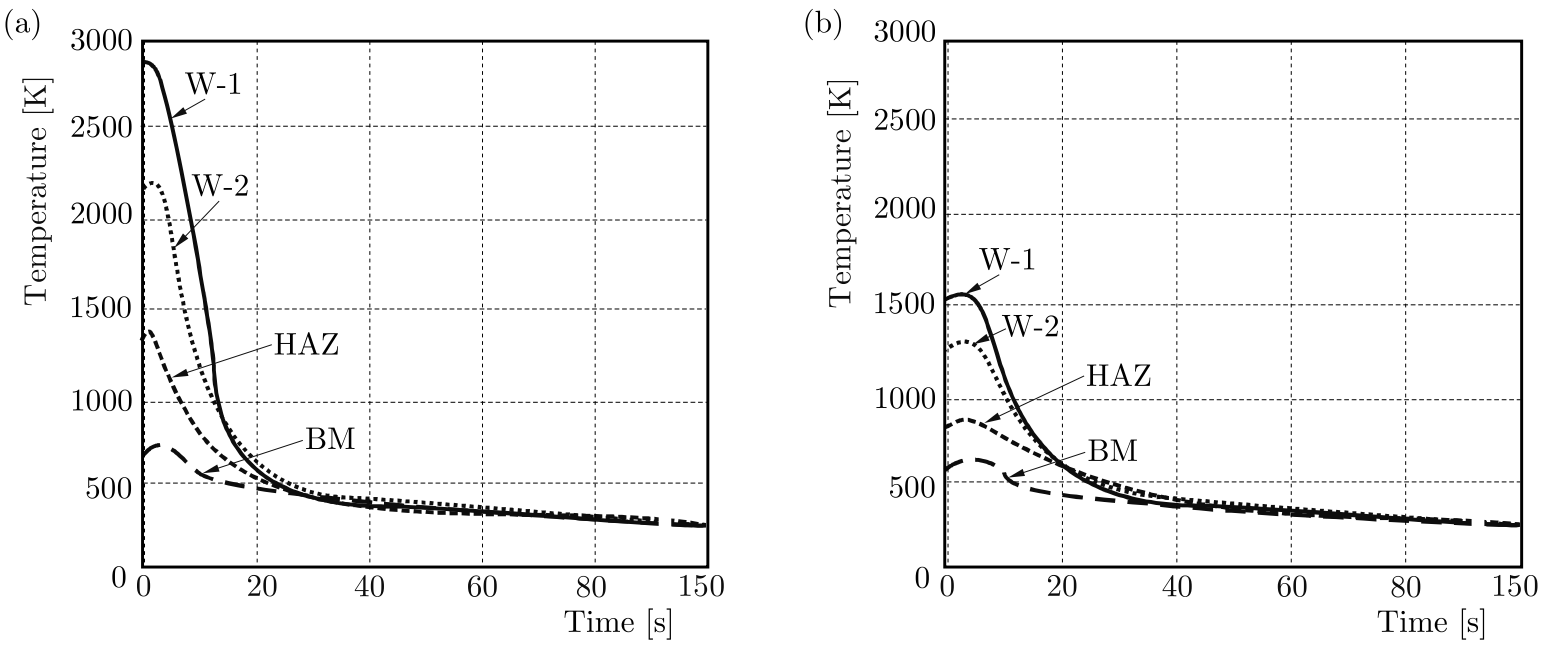

Fig. 6. The temperature distribution as a function of welding time for the zones of a weld made with the laser beam (a) and TIG (b) methods

One of the major challenges is to appropriately represent the mechanical boundary conditions. Due to thermal deformations generated in the cooling process and the fact that only a small part of the welded sheets is modelled, it is necessary to use other forms of simulation for the impacts of the operating handles in which the sheets are mounted during the welding process. The influence of the rest of the structure is mapped by introducing springs with an appropriate stiffness defined by

$$
k_{i}=\frac{E(T) A}{l_{s} L}
$$

where $k_{i}$ is the modulus of elasticity of the spring, $A$ - area of the cross section of the sample respective wall (front or side), $E(T)$ - Young's modulus of the base material in function of time, $l_{s}$ - the number of springs.

The length $L$ is determined according to the part of the steel sheet which it replaces, i.e., both the front and back wall of the sample

$$
L=\frac{1000-\text { sample width }}{2}
$$

whereas for the side walls

$$
L=\frac{1000-\text { sample length }}{2}
$$

The determined factors of the spring elasticity are assigned to this type of elements in which the length is equal to $1 \mathrm{~mm}$. All degrees of freedom are removed from the nodes at the end of the spring. A schematic method for introducing the mechanical boundary conditions is illustrated in Fig. 7. The positioning of the springs is asymmetrical to ensure lack of rigid movement.

Layers of the reduced stress calculated according to the Huber-Mises-Hencky yield criterion for the models of welds made with the laser beam and TIG methods are shown in Figs. 8 and 9 . 

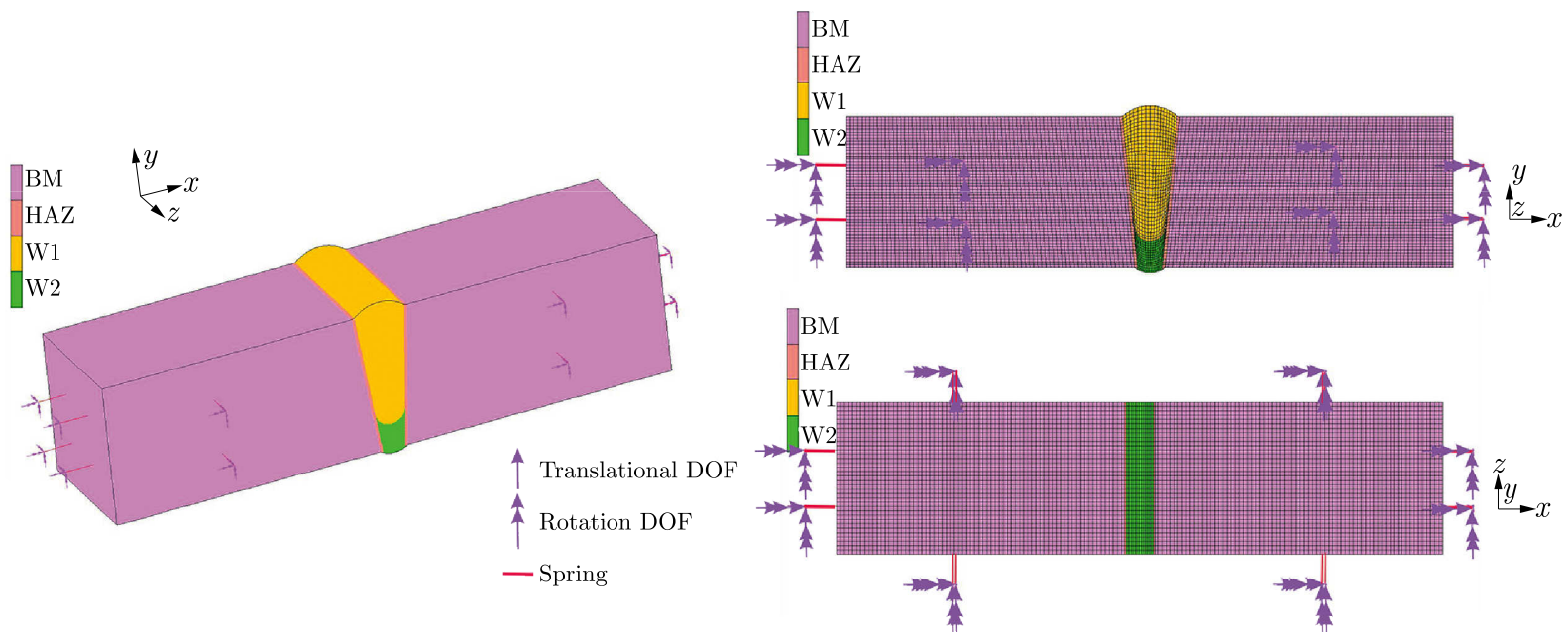

Fig. 7. Schematic of boundary conditions for the weld model created with the laser beam method
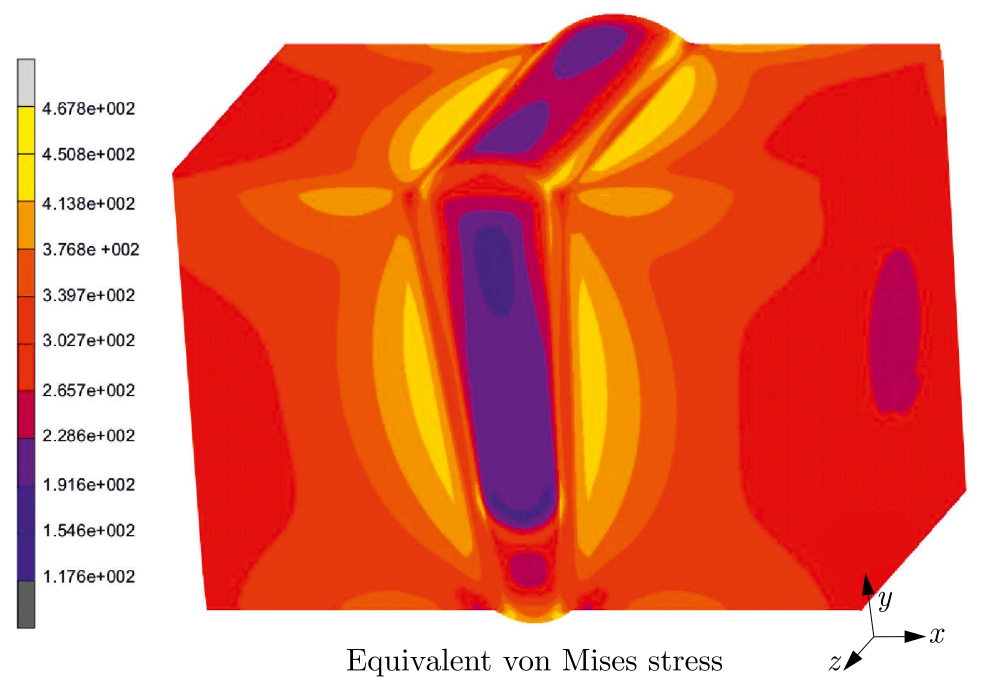

Fig. 8. Layers of the reduced stress calculated according to the Huber-Mises-Hencky yield criterion for the model of weld made with the laser beam method

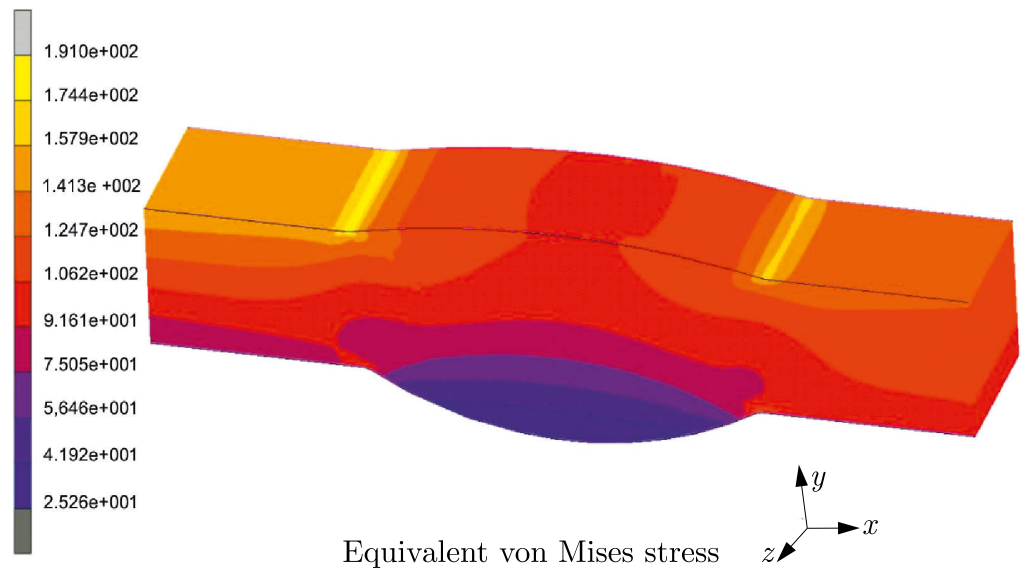

Fig. 9. Layers of the reduced stress calculated according to the Huber-Mises-Hencky yield criterion for the model of weld made with the TIG method 
The analysis of the distribution of stress calculated according to the Huber-Mises-Hencky yield criterion (red) determined with FEM (for welds made with the laser beam and TIG methods) has been compared with the experimental results (Figs. 10a and 10b). Based on the components of residual stress in both the $x$ and $y$ axis directions and formula (5.13), the reduced stress is calculated (Dyląg et al., 2007)

$$
\sigma_{\text {red }}=\sqrt{\sigma_{x}^{2}+\sigma_{y}^{2}-\sigma_{x} \sigma_{y}}
$$
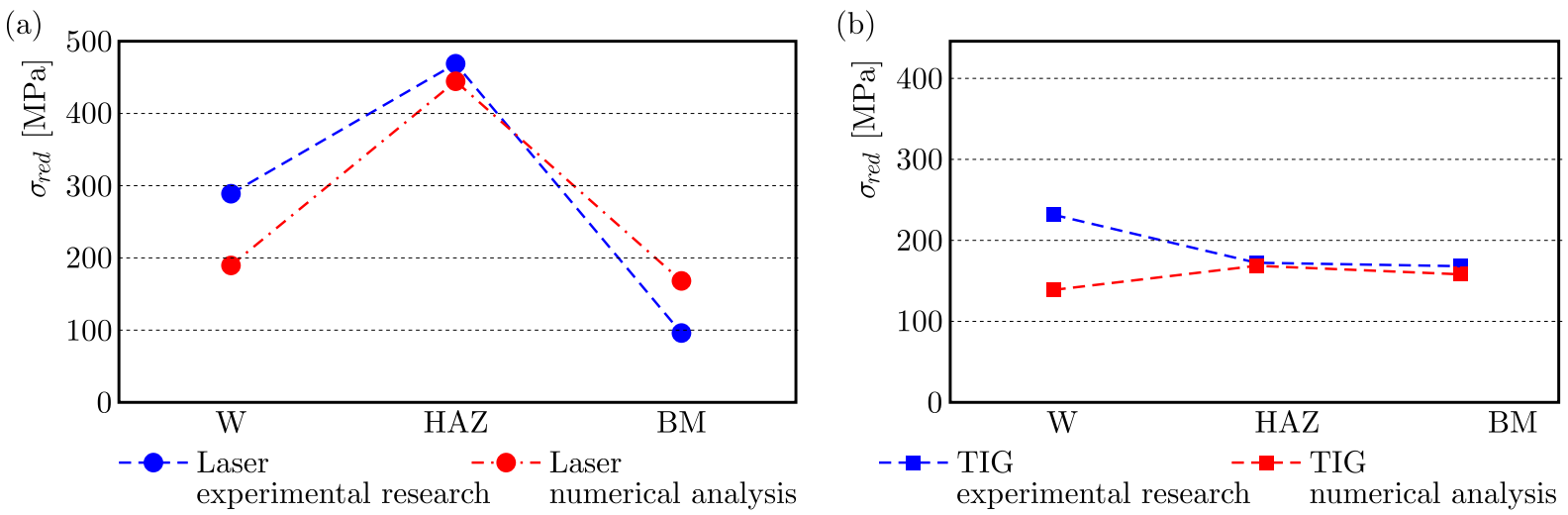

Fig. 10. Distribution of the reduced and computational stress determined experimentally and with the use of the finite element analysis of the weld (W), the heat affected zone (HAZ), and the base material (BM) of the samples made with the laser beam (a) and TIG (b) methods

The results of the experimental tests and the numerical analyses show a compliance that falls within some margin of error (Dyląg et al., 2007). The differences may be due to previously described oversimplification of the model.

\section{Conclusion}

$904 \mathrm{~L}$ welded austenitic stainless steel is of great importance in demanding structural engine-ering and, therefore, it is crucial to detect and remove any errors resulting from design and manufacturing processes. To achieve this goal, it is essential to effectively determine residual stress occurring in sensitive locations of welded joints.

The distribution of stress has been determined using the FEM, based on established thermophysical results (Nasiłowska, 2016) and mechanical properties (PN-EN 19988). Analysis of the numerical distribution of stress in comparison to experimental results shows a compliance within a margin of the measurement error. The most accurate results have been obtained for welds made with the laser beam.

The observed differences between the numerical analysis and experimental research are likely to result from oversimplification of the model.

In conclusion, this analysis suggests that future numerical simulations should take into account liquid-solid transformation and more precisely define thermal boundary conditions.

\section{References}

1. Benasciutti D., Lanzutti A., Rupil G., Haeberle E., 2014, Microstructural and mechanical characterisation of laser-welded lap joints with linear and circular beads in thin low carbon steel sheets, Materials and Design, 62, 205-216 
2. Blacha Ł., KarolczuK A., 2016, Validation of the weakest link approach and the proposed Weibull based probability distribution of failure for fatigue design of steel welded joints, Engineering Failure Analysis, 67, 1, 46-62

3. Bogdanowicz Z., NasiŁowska B., Jóźwiak P., Zasada D., 2015, Structure and mechanical properties of 1.4539 austenitic steel joints made by TIG and laser-beam welding, Solid State Phenomena, 224, 99-104

4. Dong D., Liu Y., Yang Y., Li J., Ma M., Jiang T., 2014, Microstructure and dynamic tensile behavior of DP600 dual phase steel joint by laser welding, Materials Science and Engineering, 594, $17-25$

5. Dyląg Z., Jakubowicz A., OrŁoś Z., 2007, Strength of Materials (in Polish), vol I, WNT Warszawa

6. Jiao X., Yang Y., Zhou C., 2014, Seam tracking technology for hyperbaric underwater welding, Chinese Journal of Mechanical Engineering, 22, 2, 265-269

7. Kluger K., Łagoda T., 2016, Fatigue life estimation for selected materials in multiaxial stress states with mean stress, Journal of Theoretical and Applied Mechanics, 54, 2, 385-396

8. Lee C.-H., Chang K.-H., 2014, Comparative study on girth weld-induced residual stress between austenitic and duplex stainless steel pipe welds, Applied Thermal Engineering, 63, 140-150

9. Ma J., Kong F., Liu W., Carlson B., Kovacevic R., 2014, Study on the strength and failure modes of laser welded galvanized DP980 steel lap joints, Journal of Materials Processing Technology, 214, 8, 1696-1709

10. Marc $\AA^{\circledR}$ 2011, Volume A: Theory and User Information, Copyright 2011 MSC. Software Corporation

11. Murakawa H., 2013, Residual stress and distortion in laser welding, Handbook of Laser Welding Technologies, 374-398

12. NasiŁowskA B., 2016, Fatigue life and fractures in 1.4539 austenitic steel welded joints prepared using TIG and laser beam welding methods, PhD Thesis, Military University of Technology, Warsaw, 43-47

13. Ogle M.H., Maddox S.J., 1998, Joints in aluminium, Seventh International Conference Joints in Aluminium - INALCO'98, Cambridge, UK

14. Piekarska W., 2007, Numerical Analysis of Thermomechanical Phenomena in the Laser Beam Welding - the Tempaerature Field, Phase Transformations and Stresses (in Polish), Czestochowa University of Technology, Częstochowa

15. Piekarska W., Kubiak M., 2011, Three-dimensional model for numerical analysis of thermal phenomena in laser - arc hybrid welding process, International Journal of Heat and Mass Transfer, 54, 23-24, 4966-4974

16. Piekarska W, Kubiak M., 2013, Modeling of thermal phenomena in single laser beam and laser - arc hybrid welding processes using projection method, Applied Mathematical Modelling, 37, 415, 2051-2062

17. PN-EN 10088 - 1:2014 - 12 - Stainless steels, Part 1: List of stainless steels

18. Ranatowski E., 2009, Calculational Mechanics of Welding-Physical Fundamentals of the Process (in Polish), University Publications, University of Technology and Life Sciences in Bydgoszcz

19. Susmel L., Tovo R., 2008, Molified Wöhler curie method and Eurocode 3: accuracy in predicting the multixial fatigue strength of welded joint, [In:] Lifetime Estimation of Welded Joints, T. Eagoda (Edit.), 203-207

20. TAn W., Shin Y.C., 2015, Multi-scale modeling of solidification and microstructure development in laser keyhole welding process for austenitic stainless steel, Computational Materials Science, 98, $15,446-458$ 
21. Voss O., 2011, Untersuchung relevanter Einflussgrössen auf die numerische Schweisssimulation, TU Braunschweig, Shaker Verlag, Aachen, 36

22. Zamiri Akhlaghi F., 2009, Fatigue Life Assessment of Welded Bridge Details Using Structural Hot Spot Stress Method. A Numerical and Experimental Case Study, Master Thesis, Chalmers University of Technology, Göteborg, Sweden

Manuscript received July 3, 2017; accepted for print October 26, 2017 